\title{
Analysis of Methodical Approaches to the Innovation Efficiency Assessment
}

\author{
Ilya Slobodnyak ${ }^{1, *}$ and Elena Sosedova ${ }^{2}$ \\ ${ }^{1}$ Irkutsk National Research Technical University, Irkutsk, Russia \\ ${ }^{2}$ MUP «Mortgage Agency AGO», Angarsk, Russia
}

\begin{abstract}
The article analyzes and evaluates the known methods for assessing the efficiency of innovation. Analysis methods are considered in three groups: methods based on an economic approach; methods based on a technocratic approach; complex method. The pros and cons of these methods are considered. Methodological approaches in a single enterprise may consist of one or more methods for assessing innovation. The method selection depends on the goals for the analysis. Methods for calculating the efficiency of innovations are presented, which are divided into 4 groups: simple; traditional, based on indicators of cash flow; methods based on the indicator of net profit and comparative analytical methods. Formulas for calculations are given. The presented methods of analyzing innovations may be applied at a specific enterprise in aggregate, depending on the tasks set by stakeholders, to select the most profitable innovations.
\end{abstract}

\section{Introduction}

Any enterprise in production activities is faced with the need to introduce new production technologies. This becomes especially relevant in the context of increasing competition in the sales markets. In the modern world, the appearance of new products only for a short time gives an advantage in the market for a particular enterprise, since new competitive goods and services appear in the shortest possible time. For sustainable leadership, enterprises are forced to innovate more and more often. In such a situation, the main task is the question of choosing one or another innovation, because the final result of investment and, ultimately, profit depends on this.

In modern conditions, the increase in the economic efficiency of innovative projects should be aimed at the formation of market regulation mechanisms and the introduction of modern technologies in the context of accelerated innovative development of the economy. In the modern economy, innovation is not only a material object, but also an idea that requires investment. With the support of investors, funds or banks, we get a more perfect or new material object, i.e. innovation.

Pursuant to the HSE survey conducted among 100 Russian companies (53\% of them were industrial enterprises) [HSE, 2018], 35\% of respondents face the problem of unrealistic expectations from the project results. It seems that a correct preliminary assessment of the efficiency of projects will help to solve it. [1]

\footnotetext{
* Corresponding author: slob.irk@mail.ru
} 
The main problem for Russian enterprises is the complexity, high cost and duration of the implementation process of any innovative project, therefore, the need for the development of domestic theoretical and methodological provisions for evaluating innovative projects increases. In this regard, the development of new complex methods of economic evaluation of innovative projects is additionally updated.

The state policy of the Russian Federation is aimed at creating favorable conditions for the development of innovation and investment activities of all economic entities. But the issues of professional project management have not yet found their sufficient reflection in the documents and actions of the executive state bodies. [2]

In the Address of the President of Russia to the Federal Assembly of the Russian Federation already in 2003, it was said that we should "subordinate all our decisions, all our actions so that in the foreseeable future Russia will firmly take its place among the really strong, economically advanced and influential states of the world...Russia should be and it will be a country with a competitive market economy...All this should create decent living conditions for people...All our historical experience testifies: a country like Russia may live and develop within its existing borders only if it is a strong power."

The foreign scientists emphasized that in the process of development of a post-industrial society, the formation of value chains and the promotion of innovations in various economy sectors is most influenced by institutional factors that ensure the development of innovative activity. [3]

When assessing the economic efficiency of innovations, problems arise with the use of limited resources, the choice of optimal development options, the coherence of processes occurring within the company, personnel motivation, investor interest, etc. Currently, such methods for assessing the economic efficiency of a company are required, which would allow, in conditions of high uncertainty of the innovation process, to consider the need for flexibility in making managerial decisions to choose an option for investment.

It is especially necessary to highlight such areas for comparative analysis of approaches to assessment as risk accounting, analysis of financial decisions, financial results, as well as the scope of each of the approaches. [1]

Transformations in the economy, the integration of the country's economy into world markets and the formation of new economic relations require the use of new management models and criteria for assessing the efficiency of innovation processes.

\section{Research Methodology}

Currently, there is no unified approach to assessing innovation. In addition, there is a need to develop objective methods for assessing and predicting indicators of the cost of innovative projects.

The problem of the methodology for assessing the economic efficiency for each specific enterprise engaged in innovative activities is the basis for the effective allocation of all available resources. This problem includes the following provisions:

- imperfection of criteria for assessing the efficiency of companies' activities based on traditional economic approaches;

- the need to study the innovative process of enterprise development;

- imperfection of methods for assessing intangible assets and existing intellectual property objects at enterprises;

- problems of evaluating the efficiency of innovative projects associated with radical innovations, the lack of clarity of the long-term consequences of their implementation;

- the ambiguity of the formation of factors of the market value of the enterprise;

- the need to consider risk as a factor that increases the competitiveness of an enterprise and the ability to adapt to a changing external environment. [4] 
The accumulated world experience in the field of innovation management shows that the interaction of the subjects of innovation activity as an object of research is characterized by the complexity, variability, mobility of functional states, both in temporal and spatial aspects. The multidimensionality and multifunctionality of the object of research involves the use of a variety of scientific tools (methods of simulation, economic analysis, etc.) to build quantitative estimates of the relationship between subjects and development institutions at all stages of innovation - creation, development, dissemination and use of innovations [5].

Different methodological approaches are used to determine the criteria and system of indicators to assess the efficiency of innovation. Depending on the field of application, the economic effect from the introduction of scientific and technical developments into production and from the use of new types of products is distinguished. [6]

Evaluation of the efficiency of innovative activities is designed to obtain an analysis in one of the economic dimensions - material, monetary or social, which may be expressed through improving the quality of products, reducing the time of production and circulation of goods, freeing up or saving resources, etc.

The economic effect of innovation is assessed by profit: from the sale of innovative products, the introduction of inventions, utility models, and enhanced use of production facilities. The system of indicators should:

1) form an assessment based on a retrospective analysis of production and economic activities for at least 3-5 years;

2) reflect all aspects of the organization's financial activities and be expressed in absolute, relative and specific values.

In general, the economic efficiency of innovations is determined by comparing the results of activities with the costs that ensured their achievement. [7]

The innovation assessment methodologies used today may be summarized in three groups (Fig. 1).

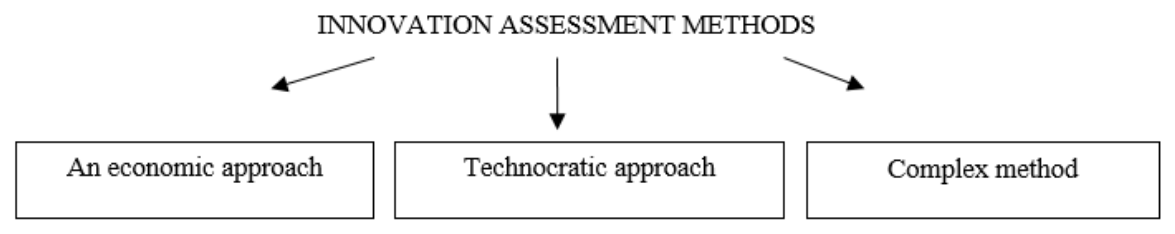

Fig. 1. Innovation assessment methods

The technocratic approach to the analysis of enterprise innovations consists in replacing old equipment with new ones and is measured on the basis of such related indicators as the volume of technical measures being introduced, the number of patented inventions and units of new technology etc. Herewith, the novelty of innovative transformations within the enterprise is assessed. The main disadvantage of the technocratic approach is that the choice of an innovative development strategy based on the calculation of comparative efficiency or expert assessment cannot act as the main method of managing the process of innovative development. Moreover, within the framework of the technocratic approach, due attention is not paid to the problem of optimality of resource allocation, in addition, the economic aspects of innovation remain undisclosed.

Economic methods for assessing the innovative development level are based on such indicators of productivity as capital productivity, labor productivity and other indicators of the optimal use of resources, investment efficiency, as well as cost indicators. However, within the framework of this approach, the main goal of strategic planning is to ensure the required increase in the volume of output with the maximum saving of resources, and not to ensure sustainable innovative development in the long term. 
Moreover, the economic approach provides for a special place for methods based on the use of cost indicators that directly reflect the efficiency of the production process. The advantage is that these methods are easy to use, and innovations are perceived as a system with a stable functional relationship between production costs and actual output. [4]

The main shortcomings of the considered methods are the following:

1) the impossibility of an accurate valuation of innovative activities, since the costs of development, implementation in production and on the market of innovations may not always be expressed in value terms;

2) the difficulty in predicting scientific and technical problems that researchers, developers and potential consumers of innovative products and technologies may face.

Based on this, the methods used for assessing innovative development are predominantly probabilistic in nature.

An integrated approach to assessing innovations includes the sequential application of structural analysis and multicriteria optimization methods to determine the normative usefulness of innovations and the cost of resources for each of them, as well as methods of systems analysis. In the structural analysis, the task of innovative development of the enterprise is divided into separate components. To make a decision on the direction of innovative development, this method makes it possible to most fully present all possible scientific, technical and economic problems.

The considered approaches (technocratic, economic and complex) are not mutually exclusive. These approaches complement each other, are associated with solving various problems and have their drawbacks. The technocratic approach overlooks the issue of the efficiency of resource allocation, and the economic approach does not consider the technical and other characteristics of innovations that cannot be valued.

The assessment methodology should be comprehensive, that is, the methodology should consider both the characteristics of innovative products and technologies that may be assessed in terms of value, as well as the qualitative characteristics. The combination of economic and technocratic approaches allows to create a special comprehensive method, evaluate the efficiency of innovation, for the correct allocation of limited resources, and also contributes to the formation of a wide applied aspect.

Each enterprise, when choosing a methodology, proceeds from the goals of assessing innovations for subsequent implementation. [8].

Methodological approaches in a single enterprise may consist of one or more methods for assessing innovation. The method selection depends on the goals for the analysis.

\section{Research results.}

All methods may be grouped into four groups:

1. Simple methods. These include:

- the average rate of return (the level of profitability of the project) - serves as a criterion for choosing one project from several alternative ones and is calculated as follows:

$$
\mathrm{RR}=\text { ЧПб/P }
$$

where RR - the average rate of return for the project; NAP - net accounting profit; $\mathrm{C}$ - average project costs;

- coefficient of efficiency of capital investments- used for comparison with the return on assets indicator: if the capital investment efficiency ratio is higher than the return on assets, then the project is recognized as effective. The indicator is calculated as follows:

$$
\mathrm{CECI}=\text { ЧП } / \mathrm{P}
$$

where NP -average annual net profit; 
- the rate of return on capital investment - allows to determine the number of years required to fully recover the initial costs. Therefore, preference is given to projects with shorter payback periods.

$$
\text { RRci=ПК/ЧП }
$$

where RRci - return on capital investment;

IC- initial capital investment in the project.

2. Traditional methods based on the use of cash flow indicators. They are most commonly used to measure innovation. These include:

- net present value, - allows to determine the final effect of the implementation of innovations in monetary terms. Therefore, the project that brings the greatest positive effect in monetary terms is applied to the implementation

$$
\text { ЧПД }=\sum_{\mathrm{t}=1}^{\mathrm{n}} \frac{\text { ЧПД1 }}{(1+\mathrm{i})}-\text { ИЗ }
$$

where NPV - net present value in case of a one-time implementation of investment costs; IC - the sum of one-time investment costs for the implementation of an innovative project;

$i$ - discount rate;

$n$ - number of intervals in $t$ period;

- profitability index - shows the level of payback of the project or the degree to which the costs of implementing the project are covered by income from its implementation. Therefore, the recommended value for this indicator is more than 1 .

The indicator is calculated pursuant to the formula:

where $P I$ - profitability index;

$$
\text { ИД }=\sum_{\mathrm{t}=1}^{\mathrm{n}} \frac{\text { чдП1 }}{(1+\mathrm{i})^{\mathrm{t}}} / \text { ИЗ }
$$

- the profitability index - has a more limited semantic meaning than the profitability index, since the calculation considers the investment flow, a significant part of which is depreciation, and the time factor is not considered in the calculations

$$
\mathrm{PI}=\text { ЧП/ИЗ }
$$

where $P I-$ profitability index;

- payback period, - an indicator that allows to determine the number of years (months) required to return the funds invested in an innovative project due to the return on this project

$$
\text { РР=ИЗ/ЧДП }
$$

where PP - payback period of investment costs for the project;

$\mathrm{NCF}$ - average annual amount of net cash flow for the period of operation of the project.

The main advantages of this method (in addition to ease of understanding and calculations) are the certainty of the amount of initial investment, the ability to rank projects by payback periods, and, consequently, by the degree of risk, since the shorter the repayment period, the greater the cash flows in the first years of the implementation of the innovative project, which means that the conditions for maintaining the liquidity of the enterprise (firm) are better.

However, the disadvantage of this method is that the accuracy of the calculations is distorted in the case of significant project terms due to the fact that the time factor is not considered in the calculations;

- discounted payback period - is a modification of the previous indicator, its calculations consider the correction for the time factor

$$
\mathrm{PP}=\frac{\text { Из }}{\sum_{\mathrm{i}=1}^{\mathrm{n}} \frac{4 Д \Pi}{(1+\mathrm{i})^{\mathrm{n}} \mathrm{t}}}
$$


where NCF - the average amount of net cash flow for individual intervals of the total period of operation of the innovation project;

- the internal rate of return, shows the level of profitability of the innovative project, expressed by the discount rate, which is reduced to the real value of investment costs. There is no standard formula for calculating this indicator, but it may be obtained by mathematical transformations from the following formula:

$$
\sum_{\mathrm{i}=1}^{\mathrm{n}} \frac{\text { чДП }}{(1+\text { ВНД })^{\mathrm{t}}}=\text { ИЗ }
$$

This method boils down to finding such a discount rate at which the present value of the income expected from the project will be equal to the present value of the required investments.

- the break-even point of the project, - is used to calculate such a volume of new products, the implementation of which ensures the break-even of an innovative

where $\mathrm{P}$ - the break-even point of the project;

$$
\mathrm{P}=\frac{\mathrm{C}}{Ц-\mathrm{B}}
$$

$\mathrm{C}$ - conditionally fixed costs;

$\operatorname{Pr}$ - unit price;

$\mathrm{B}$ - variable costs per unit of output;

3. Methods based on the net income indicator:

- net profit - the main indicator for investors, is calculated as the difference between the proceeds from the sale of products and the costs of their production, including taxes.

where P- accounting profit;

$$
\mathrm{P}=\mathrm{B}_{6}-(\mathrm{C}+\mathrm{H})
$$

$\mathrm{R}_{\sigma}$-accounting revenue;

C- production cost;

T-tax.

The method has several advantages. This is, first of all, the simplicity and obviousness of calculations, a direct connection with the indicators of the accepted accounting and analysis. However, it also has serious drawbacks. For instance, the question arises which year to take in the calculations. Since annual data are used, it is difficult, if not impossible, to select the most representative year for the project. All of them may differ in terms of production levels, profits, interest rates and other indicators. This disadvantage, which is a consequence of the static net profit, may be eliminated by calculating the profitability (profitability) of the project for each year. However, even after this, the main drawback remains, since the distribution over time of the net flow and outflow (income and expense) of capital during the life of the investment object is not considered. Then the profit earned in the initial period is preferable to the profit earned in later years, and it is difficult to choose between the two alternatives if they have different profitability over a number of years.

In this case, it is necessary to apply cost discounting formulas. Discounting is the comparison of indicators of different times by bringing them to the value in the initial period. To bring costs, results and effects at different times, the discount rate is used, which is equal to the rate of return on capital acceptable to the investor. Technically, it is convenient to reduce the costs, results and effects that occur at the t-th step of calculating project implementations to the base point in time by multiplying them by the discount coefficient determined for the constant discount rate.

- the total amount of the given investments - implies the calculation of their value, considering the increase in investments and discounting

$$
\mathrm{K}_{\mathrm{n}=} \sum_{\mathrm{i}=1}^{\mathrm{m}} \mathrm{K}_{1}(1+\mathrm{r})^{\mathrm{i}}+\sum_{\mathrm{i}=\mathrm{m}}^{\mathrm{n}} \frac{\mathrm{K}_{1}}{(1+\mathrm{r})^{\mathrm{i}}}
$$


where $K_{n}-$ the total amount of the given investments, considering their increase and discounting;

$\mathrm{K}_{\mathrm{i}}$ - investments per year $\mathrm{i}$;

$\mathrm{m}$ - the number of years of investment prior to the commissioning of the facility;

$\mathrm{n}$ - the number of years of investment after the facility was put into operation;

- discounted payback period

where $T_{2}$ - discounted payback period

$$
\mathrm{T}_{\mathrm{r}}=\frac{\mathrm{K}_{\mathrm{n}}}{\Pi}
$$

$P$ - average annual profit;

- the coefficient of efficiency of innovations - the coefficient inverse to the discounted payback period

where E- innovation efficiency ratio

$$
\mathrm{E}=\frac{1}{\mathrm{~T}_{\mathrm{r}}}
$$

4. Methods based on comparative analytical performance indicators:

- percentage of production cost reduction -

$$
\mathrm{Ec}=\left(\frac{\mathrm{C}_{1}}{\mathrm{~T}_{1}}+\frac{\mathrm{C}_{0}}{\mathrm{~T} \Pi_{0}}-1\right) 100=\frac{\mathrm{E}_{\mathrm{c}}}{\mathrm{C}_{\mathrm{p}}} 100=\left(\mathrm{B}_{\mathrm{mpi}}+\mathrm{B}_{\mathrm{mp} 0}-1\right) 100,
$$

where $\mathrm{Ec}$ - percentage of production cost reduction;

$\mathrm{TP}_{1}, \mathrm{TP}_{0}-$ the volume of production of the reporting and base periods in comparative prices;

$\mathrm{C}_{1}, \mathrm{C}_{0}-$ cost of production of the reporting and base periods in comparative prices;

$\mathrm{B}_{\mathrm{mp} 1}, \mathrm{~B}_{\mathrm{mp} 0}$ - expenses per ruble of products in the reporting and base periods;

$\mathrm{E}_{c}-$ relative savings in production costs due to cumulative impact of

all technical and economic factors;

$\mathrm{C}_{\mathrm{p}}$ - the estimated cost of production.

- increase in potential profit

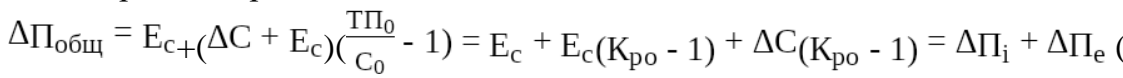

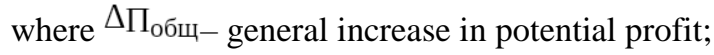

$\Delta \mathrm{C}$ - total increase in production costs in the reporting period compared

to the baseline;

$\triangle \mathrm{Pi}$ - profit growth due to intensive factors;

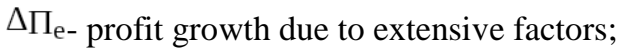

- increase in added value

$$
\Delta \text { ДВ }_{\text {общ }}=\Delta \text { ДВ }_{\mathrm{i}}+\Delta \text { ДВ }_{\mathrm{e}}=\mathrm{E}_{\mathrm{c}} \cdot \mathrm{K}_{\mathrm{p} 0}+\Delta \mathrm{C}_{\left(\mathrm{K}_{\mathrm{p} 0}-1\right)}+\Delta 3
$$

where $\triangle$ ДВ

$\triangle Д \mathrm{~B}_{\mathrm{i}}$ - increase in value added due to relative cost savings;

$\triangle Д \mathrm{~B}_{\mathrm{e}}$ - increase in value added due to extensive factors [9].

\section{Discussion}

Analysis of the results considered within the framework of these approaches showed that all methods have drawbacks that do not allow them to give an accurate and objective result: the first group of indicators does not consider the time factor in the calculations; the second 
group involves the inclusion of depreciation in the composition of the cash flow covering innovation costs, which is incorrect and overestimates the real efficiency of projects; the third, fourth groups of indicators - each individually reflects a rather narrow range of performance indicators, as a result of which the efficiency is calculated in a rather onesided way; changes in the indicators of the financial condition of the enterprise before and after the implementation of innovative projects are not considered; they do not contain at least approximate sectoral benchmarks for each indicator, although there are features of the implementation of activities in trade and, e.g., mechanical engineering or metallurgy; they do not contain recommendations regarding the consideration and influence of the factor of possible change in the conditions for the implementation of an innovative project in the future, which cannot always be predicted with high reliability.

The presented methods of analyzing innovations may be applied at a specific enterprise in aggregate, depending on the tasks set by stakeholders, to select the most profitable innovations.

\section{Conclusion}

The above analysis shows that in international and Russian practice there are many approaches to assessing innovations, but all of them cannot be considered universal and are applied differentially depending on the tasks set for using the results of scientific achievements in the form of intellectual property to increase the efficiency and competitiveness of industries, products or services. Herewith, an individual, specific assessment method is selected and implemented, based on considering all legal, economic, technical and other aspects. Considering that an innovative project is characterized by a number of specific properties, which at the same time vary depending on the stage of the project's life cycle, the development of theoretical provisions, methods, as well as practical recommendations for the formation and management of innovative projects is required. Starting from the pre-investment planning stage, the level of innovation and patentability of the technologies used for the creation and operation of capital objects, their competitiveness - these are the basic indicators of the innovative component of the project, which are decisive when deciding on the implementation of the project. [10]

The article systematizes methods for assessing innovations for the selection of which it is necessary to consider the characteristics of each project and the objectives of the analysis.

\section{References}

1. D.A. Lyubimenko, E.D. Vaisman, Computer science 47(4), 718 (2020). DOI 10.18413/2687-0932-2020-47-4-718-728.

2. R.I. Hansevyarov, O.K. Maksimova, Methodological approaches to assessing the effectiveness of innovative projects. Economic sciences (2015)

3. J. Schumpeter, Theory of economic development. Translated V.S. Avtonomova et al., 455 p. (Moscow: Progress, 1982)

4. S.N. Yashin, I.L. Tukkel, E.V. Koshelev, S.A. Makarov, Yu. S. Korobova, Estimation of the Efficiency of Innovative Activity, Textbook (Nizhny Novgorod Publishing House of Nizhny Novgorod State University, 2018)

5. G.Z. Tishchenkova, G.A. Petushkova, M.V. Shelomentseva, A.V. Naumenkov, Bulletin of the Altai Academy of Economy and Law 10, (2020)

6. E.V. Nikiforova, A.A. Aldoshkin, Azimuth of scientific research: economics and management 6(4(21)) (2017) 
7. O.V. Donets, P.N. Maidanevich, Methodological approaches to assessing the effectiveness of innovative activities. Economic and social sciences (2015)

8. V.E. Barkovskaya, Bulletin of the Astrakhan State Technical University. Series: Economics 3(27) (2020) DOI: 10.24143/2073-5537-2020-3-27-34

9. I.A. Pedersen, Analysis of approaches to assessing the effectiveness of innovations and determining the directions of their improvement. Problems of the formation of a new economy of the XXI century: materials II Mizhnar. nauk.-practical. Conf., In 5 volumes, Dnipropetrovsk: Bila K.O. 3, 126 (2009)

10. Yu. A. Dolzhenko, MGSU Bulletin 2 (2015) 